\title{
The Effect of Refractivity on Propagation at UHF and VHF Frequencies
}

\author{
I. Alam, ${ }^{1}$ N. Mufti, ${ }^{2}$ S. A. A. Shah, ${ }^{1}$ and M. Yaqoob ${ }^{1}$ \\ ${ }^{1}$ Department of Electrical Engineering, Bahria University, Shangrilla Road, Sector E-8, Islamabad, Pakistan \\ ${ }^{2}$ Department of Electrical Engineering, University of Engineering and Technology, Mardan Campus, Mardan, Pakistan \\ Correspondence should be addressed to I. Alam; ialam.buic@bahria.edu.pk
}

Received 20 June 2016; Revised 22 August 2016; Accepted 26 October 2016

Academic Editor: Larbi Talbi

Copyright (c) 2016 I. Alam et al. This is an open access article distributed under the Creative Commons Attribution License, which permits unrestricted use, distribution, and reproduction in any medium, provided the original work is properly cited.

\begin{abstract}
This paper is using weather parameters to investigate the effect of refractivity on propagation in the first kilometer of the atmosphere over the English Channel for a long transhorizon path of $140 \mathrm{~km}$. Different refractivity profiles are constructed based on meteorological data taken from the UK Meteorological Office in order to investigate the effects of refractivity on propagation. The analysis is made for the hourly experimental path loss between the transmitter and receiver obtained from the experimental setup comprised of two communication links. The frequency of operation of the first link is $2015 \mathrm{MHz}$ and that of the second link is $240 \mathrm{MHz}$. Parabolic equation method is modelled to get an hourly modelled path loss corresponding to each hourly experimental path loss to be analyzed for the said communication links. The correlation between the modelled path loss and experimental path loss is computed for refractivity distribution recommended by the ITU and predicted profiles. It is inferred from the simulated and experimental results that little or no influence exists by the evaporation duct upon path loss at $2015 \mathrm{MHz}$ specifically for a long path of $140 \mathrm{~km}$ over the sea.
\end{abstract}

\section{Introduction}

Radio communication links are significantly affected by highly variable propagation conditions of the atmosphere. Weather parameters can be used to predict distribution of refractivity responsible for these conditions. Assessing these variable conditions and providing a better prediction of refractivity potentially help the designers of communication, navigation, and radar systems to improve performance. Refractivity predictions are very useful in many applications of wireless communication, navigation, and surveillance systems. Such predictions are important in order to cope with the problems encountered where anomalous propagation and unpredicted path loss affect the performance of these systems. The influence of these unpredicted propagation effects is sometimes so severe that a complete communication breakdown occurs between transmitter and receiver or a radar misses its target completely. It is mandatory for a propagation engineer to take into account the deviation of the propagating wave due to the changes in the distribution of refractivity.
In this paper the phenomenon of ducting where a propagating wave trapped in the form of a duct is investigated in the first kilometer of the atmosphere over the English Channel for oversea propagation at UHF $(2015 \mathrm{MHz})$ and VHF $(240 \mathrm{MHz})$ frequencies in the radio spectrum. Ducting is classified into four different types with emphasis on the evaporation duct over the sea. The most important parameter to consider the effect of evaporation duct or the depth of the electromagnetic duct is evaporation duct height $(\mathrm{EDH})$ which in turn determines how refractivity is affecting communication between transmitter and receiver.

The theory of the methodology used in this research for the simulation of radio wave propagation is provided in Section 2 where it is described in detail why the method of parabolic wave equation is selected. The experimental setup is provided in Section 3 while the construction of modified refractivity profiles is given in Section 4 . Analysis and results from the implemented model are discussed in Section 5 with a number of cases for different EDHs for two oversea communication links. These links are labelled as "Link 1" for 
long path at UHF and "Link 2" at VHF. Finally, the conclusion of the work is presented in Section 6.

\section{Parabolic Equation Method}

Different methods and techniques for measuring refractivity, for example, refractometer, radar, GPS occultation, and lidar, are in use. These methods are limited in many ways especially their practical implementation. For instance, the performance of lidar is limited by the background noise levels and high extinction conditions [1]. The parabolic equation method (PEM) was originally proposed by [2] for long range radio wave propagation in 1944. In 1946, [3] provided PEM solution to electromagnetic waves problems. In 1977, [4] decomposed an elliptical wave equation into two equations through the choice of an arbitrary constant reference wave number, one of which resulted in the development of the standard parabolic equation (also called the narrow angle parabolic equation) [5]. This technique gained popularity quite quickly and a number of researchers started using it by developing different solution methodologies [6-11]. This technique has been used for many years to model radio wave propagation in the troposphere especially over the sea.

PEM provides a reliable wave solution for the prediction of electromagnetic field in which real refractivity profiles are considered unlike the initially used rays-based solution techniques and mode theory-based solutions techniques. In contrast to PEM, ray-based and mode theory-based solution techniques like geometrical optics [12], physical optics [13], normal mode analysis, coupled mode analysis [14], and hybrid methods [15] resulted in an inappropriate solution [16].

The basic theoretical development of parabolic equation starts with the reduction of the well-known 3-dimensional Maxwell's equations, representing the existence of a full electromagnetic wave, to 2-dimensional time harmonic Helmholtz equations in range $(x)$ and altitude $(z)$. This reduction is performed under the considered "paraxial propagation domain" in which the energy of the propagating wave travels in the form of a cone having vertex at the transmitting antenna and making a small "grazing angle" (term used for angle made by the wave with the horizontal direction of wave propagation). The horizontal and vertical polarized components of the field are propagating independently inside the cone with a time dependence of $e^{-i \omega t}$ where $\omega$ is the angular frequency of the propagating wave and $t$ is the time [17].

Generally, two methods of finite difference method (FDM) [18] and split step Fourier transform (SSFT) [19] are used to get the numerical solution of the reduced parabolic wave equation. An excellent comparative description of the two methods can be found in [20]. The first method requires huge computational resources because of getting the solution of large system of simultaneous equations in large number of unknowns and the specification of radiation boundary conditions [21] on a closed domain [22]. FDM solves the wave equation explicitly in the time domain only without dropping the carrier frequency and hence a great amount of computing time and storage is needed. In this research SSFT algorithm is chosen as it uses larger range steps, which makes it more efficient computationally.

Split step Fourier transform technique works on the principle of marching the solution forward in short steps until converged solution is obtained. In other words, the solution to the problem of interest is obtained by splitting the solution in a series of phase screens (steps) orthogonal to the direction of propagation of the field. First the initial field is propagated and then a phase screen modulated by refractive index variations is applied to it. The resulting field is then forward propagated through the medium to the next phase screen and so on. A more detailed technical mathematical derivation for this technique with its application to tropospheric propagation problems as well as its implementation by using different solution methods can be found in [17]. In order to investigate the characteristics of refractivity and its impact on wave propagation, a propagation model is developed in MATLAB using PEM. The greater details about mathematical formulation of the propagation model using PEM and having implementation in MATLAB can be found in [18-21]. The model is used to get an hourly modelled path loss corresponding to the experimental path loss for all communication links.

\section{Experimental Setup}

The experimental setup is comprised of two long (One at UHF and other at VHF) transhorizon paths of $140 \mathrm{~km}$ over the English Channel. The first link named as "Link 1" is from Jersey St John's Quarry to Portland Bill Lighthouse at $2015 \mathrm{MHz}$ frequency. Similarly, the second link named as "Link 2" is from Jersey St John's Quarry to Alderney (Isl De $\mathrm{Raz}$ ) at $2015 \mathrm{MHz}$ frequency.

The height of the UHF transmitting antenna at Jersey St John's Quarry is $16.5 \mathrm{~m}$ (AMSL) and that of VHF antenna is $17.5 \mathrm{~m}$ (AMSL). The height of the receiving antennas at Portland Bill Lighthouse is 12 and $13.4 \mathrm{~m}$ (AMSL) for $\mathrm{UHF}$ and VHF, respectively, with vertical polarization. The experimental half power beam width of the antennas is $17^{\circ}$.

For each communication link a set of 6000 values of the received signal strength per hour (i.e., 25 values in 2 seconds, 4 times per minute) were recorded by both receiving antennas. The median value for each set of 6000 recorded received signal strengths is calculated which resulted in a new data set termed as an "hourly data set." The analysis made in this work is based on the hourly data set; the reason for doing so is that the meteorological data is available in an hourly format. From the median set of hourly data experimental path loss (EPL) is calculated for each communication link according to the relation given in

$$
\mathrm{EPL}=\mathrm{CF}-P_{R}
$$

where $P_{R}$ is the recorded received signal strength in $\mathrm{dBm}$ and $\mathrm{CF}$ is the conversion factor in $\mathrm{dBm}$ from signal strength $(\mathrm{dBm})$ to path loss $(\mathrm{dB})$.

The conversion factor (CF) is used to take into consideration all the gains and losses at the transmitters, receivers, 
TABLE 1: Measured values for different parameters in the experimental setup [23].

\begin{tabular}{lccccccc}
\hline Link/parameter & $P_{s(\mathrm{Tx})}(\mathrm{dBm})$ & $P_{A(\mathrm{Tx})}(\mathrm{dB})$ & $L_{\mathrm{fd}(\mathrm{Tx})}(\mathrm{dB})$ & $G_{(\mathrm{Tx})}(\mathrm{dB})$ & $P_{A(\mathrm{Rx})}(\mathrm{dB})$ & $L_{\mathrm{fd}(\mathrm{Rx})}(\mathrm{dB})$ & $G_{(\mathrm{Rx})}(\mathrm{dB})$ \\
\hline Link 1 & 9.3 & 39.4 & -4.5 & 14 & 14.5 & -4.5 \\
Link 2 & 9.3 & 39.4 & -4.5 & 14 & 0 & -4.5 & 21.5 \\
\hline
\end{tabular}

TABLE 2: Geographical coordinates of all the weather stations along with their heights.

\begin{tabular}{lccc}
\hline Weather station & Latitude & Longitude & Height AMSL (m) \\
\hline Portland & 50.517 & -2.45 & 52 \\
Jersey Airport & 49.208 & -2.196 & 84 \\
Guernsey Airport & 49.433 & -2.6 & 102 \\
Channel Light & 49.9 & -2.9 & 5 \\
Vessel (CLV) & & & \\
\hline
\end{tabular}

amplifiers, feeders, and so forth. The value of CF for "Link 1 " and "Link 2" are 89.7 and $68.2 \mathrm{dBm}$, respectively. Conversion factor is a specifically calculated value obtained by using different parameters for each link which converts the recorded received signal strength into path loss. The formula for getting this value is given in (2). The detailed link budget and calculation of the individual parameters used in (2) is given in [24]. The values for all these parameters are tabulated in Table 1 to get a corresponding CF value for each link.

$$
\begin{aligned}
\mathrm{CF}= & P_{s(\mathrm{Tx})}+P_{A(\mathrm{Tx})}-L_{\mathrm{fd}(\mathrm{Tx})}+G_{(\mathrm{Tx})}+P_{A(\mathrm{Rx})}-L_{\mathrm{fd}(\mathrm{Rx})} \\
& +G_{(\mathrm{Rx})},
\end{aligned}
$$

where $P_{s(\mathrm{Tx})}$ is the power of transmitting source in $\mathrm{dBm}$; $P_{A(\mathrm{Tx})}$ and $P_{A(\mathrm{Rx})}$ are the power gains of the amplifiers at the transmitter and receiver systems in $\mathrm{dB}$, respectively; $L_{\mathrm{fd}(\mathrm{Tx})}$ and $L_{\mathrm{fd}(\mathrm{Rx})}$ are the feeder losses at the transmitter and receiver sites in $\mathrm{dB}$, respectively; $G_{(\mathrm{Tx})}$ and $G_{(\mathrm{Rx})}$ are the gains of the transmitter and receiver antennas in $\mathrm{dB}$, respectively.

The meteorological data, for example, temperature, pressure, humidity, and so forth, used in this research were taken from four weather stations. This data is used to find the value of refractivity or modified refractivity or $M$ profiles (see Section 4). The geographical coordinates of these weather stations and their heights above mean sea level are given in Table 2. All the weather stations are in the vicinity of the English Channel and are close to the sites of the experimental setup.

\section{4. $M$ Profile Construction}

Different types of $M$ profiles are constructed to see their effect on propagation. " $M$ Profile 1 " is constructed from the measured meteorological data for each hour up to a height of $102 \mathrm{~m}$. Above this height standard atmospheric gradient of $118 \mathrm{MU}$ per $\mathrm{km}$ is used to construct the remaining portion of the profile. For this purpose, the hourly meteorological refractivity data, available at the heights of weather stations, are used. Although the weather stations are at different geographical locations, however their range difference is insignificant and can be ignored. This is due to the approximation of horizontally independent refractivity as a reasonable case usually applied in PEM [25]. The range difference is not effective when the variations in refractivity are on a small scale (where the distance between transmitting and receiving sites is less than $100 \mathrm{~m}$ ). When the variations in refractivity are on a large scale the troposphere is stratified in horizontal layers due to the effect of gravity [26]. Linear interpolation is performed to get the values of refractivity for heights lying between the heights of weather stations.

" $M$ Profile 2" is obtained from the available meteorological data up to a height of $102 \mathrm{~m}$ and above this height ITU recommended values are used as described by ITU-R P.453-10 [27] using the monthly mean change in refractivity for February, May, August, and November as 40, 50, 50, and $45 \mathrm{NU}$ per km, respectively. For the remaining period a linear interpolation is made between the two available consecutive monthly values. These obtained values for March, April, June, July, September, October, December, and January are given as $43.33,46.66,50.00,50.00,48.33,46.66,43.33$, and $41.66 \mathrm{NU}$ per km, respectively. The ITU-R P.453-10 [28] recommended value for surface refractivity equal to $315 \mathrm{NU}$ is used.

" $M$ profile 3" is constructed from the actual meteorological data up to $102 \mathrm{~m}$ height and standard atmospheric gradient above $102 \mathrm{~m}$ in the same manner as profile 1; however the tidal variations included in this profile make it different from $M$ profile 1 . From the available tidal data (4 values per day) obtained from British Broadcasting Corporation (BBC), linear interpolation is made to get hourly tidal variations for each site for the period of the experiment. The heights of transmitting and receiving antennas for each communication link in each model run were adjusted accordingly to include the effect of high and low tides at the time of occurrence.

" $M$ Profile 4" is the tidal version of " $M$ profile 2" where compensation for the tidal variations is made by including the available tidal data in the same way as done in the case of " $M$ profile 3."

The four $M$ profiles are further adapted to include the effect of an evaporation duct up to the altitude $52 \mathrm{~m}$. The values of $\mathrm{EDH}$ used are $0,10,20$, and $30 \mathrm{~m}$. The $M$ profile representing $\mathrm{EDH}$ of $0 \mathrm{~m}$ means that no effect of the evaporation duct is included and the meteorological values are considered only as a reference case. For each $M$ profile the linear variation in refractivity between the two consecutively available meteorological values at a height of 1 and $51 \mathrm{~m}$ is adapted by exponentially varying refractivity values using (3) [17]. For example, " $M$ profile 1 with EDH 10 m" means that the $M$ profile is a combination of exponential data between $0 \mathrm{~m}$ and $10 \mathrm{~m}$, meteorological data from 11 to $102 \mathrm{~m}$, and standard data above $102 \mathrm{~m}$.

$$
M=M_{0}+0.125 \times\left(z-E_{\mathrm{dh}} \times \log _{10}\left(\frac{z+z_{0}}{z_{0}}\right)\right),
$$


TABLE 3: Number of simulations performed in each month for each frequency (all $M$ profiles).

\begin{tabular}{lcc}
\hline Month/link & Link 1 & Link 2 \\
\hline July & 673 & 686 \\
August & 672 & 671 \\
September & 682 & 680 \\
October & 716 & 413 \\
November & 712 & 175 \\
December & 571 & 157 \\
January & 694 & 34 \\
February & 619 & 69 \\
March & 708 & 0 \\
April & 714 & 0 \\
May & 677 & 458 \\
June & 664 & 664 \\
\hline
\end{tabular}

where $M_{0}$ is the value of modified refractivity at the Earth's surface; $z_{0}$ is Jeske's roughness length equal, over the sea, to $0.00015 \mathrm{~m}$; and $E_{\mathrm{dh}}$ is the evaporation duct height in metres.

\section{Discussion and Analysis}

The effect on path loss can be analyzed by changing some of the basic parameters like evaporation duct height, antenna height, frequency of operation, distance between antennas, and so forth, to get improved results from the simulations. These parameters are changed in a suitable manner for a range of arbitrary values depending on getting accurate output results in terms of path loss which were also validated through some other means, for example, theatrical calculation. The characteristic curves are analyzed for all these parameters used in the model. The results of such analysis are not shown in this paper as it was purely to validate the implemented model.

The minimum and maximum value for evaporation duct height used in this work are $0 \mathrm{~m}$ and $30 \mathrm{~m}$, respectively. The increase from 0 to $30 \mathrm{~m}$ in step size of $10 \mathrm{~m}$ is performed to see the effect of the change in the refractivity profile on the propagation at UHF and VHF. The number of simulation runs for each frequency and month is based on how many hourly experimental values are available; that is, a simulation corresponding to the measured weather data for each hour is performed. Table 3 presents the number of simulation runs performed in each month according to the available experimental path loss values in the hourly data set. The observed path loss values are correlated with those produced by the simulation runs. Clearly the amount of data available will affect the correlation.

The correlation analysis is started by looking at the data for the complete period of the experiment. Although it was not really expected to have some useful output from the analysis of huge data for a whole year, it was worth looking in case it did. In the annual analysis, all the obtained results of modelled path loss for the whole year of investigation are correlated with the experimental path loss for all the communication links and all the $M$ profiles. This is repeated for each of the four selected evaporation duct heights, which resulted in a total of 32 correlation coefficients as shown in Table 4 . The value of correlation coefficient obtained from the comparison of each experimental path loss to the modelled path loss is quantified as insignificant if it lies in the range of -1.0 to 0.2 , significant if it lies in the range of 0.2 to 0.6 , and highly correlated if it lies in the range of 0.6 to 1.0 .

Monthly correlation coefficients for the four $M$ profiles and evaporation duct heights in case of "Link 1 " are presented in Figure 1. The $p$ value is plotted with each bar of correlation coefficient which shows the confidence level of that value of correlation coefficient. The $p$ value of more than 0.1 represents less than $10 \%$ confidence in the output and hence such correlation coefficients are not counted as effective in this analysis.

For "Link 1," there are two months (i.e., July and August) where the correlation coefficient is significant for EDH $0 \mathrm{~m}$. " $M$ Profile 1 " is giving the best correlation among all the profiles. It has some significant correlation in the month of April as well. In April, " $M$ profile 1" is giving significant correlation coefficient for EDH $0 \mathrm{~m}$ and insignificant correlation coefficient for EDH $30 \mathrm{~m}$. The annual correlation coefficient value for " $M$ profile 1 " is also the highest $(0.2$ for EDH $0 \mathrm{~m})$ among the other $M$ profiles as shown in Table 4 . Since they have some of the highest correlation coefficients, July and April are chosen for further analysis.

When modelled and experimental path losses are further analyzed for July, some observations in the experimental path loss (e.g., around 17th and 29th July) are made which are followed by the fluctuation in the modelled path loss. However, there are some fluctuations (e.g., around 9th, 10th, and 15th July) which are not followed by the modelled path loss. These fluctuations in the experimental path loss may not be due to the variations in refractivity. Similarly, the results for April for EDH equal $30 \mathrm{~m}$ when " $M$ profile 1 " is used as input to the model. The modelled path loss is found to be almost at a constant level where the experimental path loss is changing. It is due to the very small change in the obtained values of refractivity from the weather stations which effectively yielded an insignificant correlation between the modelled and experimental path losses.

Figure 2 shows monthly correlation coefficients with $p$ values for all the $M$ profiles and evaporation duct heights for "Link 2." For " $M$ profile 1," " $M$ profile 3," and " $M$ profile 4 ," the $p$ values are high and hence the correlation coefficients are outside the confidence level of $10 \%$. This is true for all the evaporation duct heights. Even for " $M$ profile 2," mostly insignificant correlation coefficients exist; for example, for $\mathrm{EDH} 10 \mathrm{~m}$ all the monthly correlation coefficients are insignificant except in November and April.

The very small values of annual correlation coefficients, for " $M$ profile 1, , " $M$ profile 3 ," and " $M$ profile 4 " at all the evaporation duct heights, confirm that only " $M$ profile 2 " is found to be the best profile for "Link 2." " $M$ Profile 2 " has significant correlation coefficient of 0.49 and 0.38 for EDH 30 and $20 \mathrm{~m}$, respectively.

The monthly correlation coefficients for profile 2 at EDH $30 \mathrm{~m}$ are shown in Figure 2(d) where most of the correlation coefficients are above the level of 0.3 with high peak of 0.38 in 
TABLE 4: Annual correlation coefficients for all the communication links and $M$ profiles for (a) EDH 0 m, (b) EDH $10 \mathrm{~m}$, (c) EDH $20 \mathrm{~m}$, and (d) EDH $30 \mathrm{~m}$. EDH is the evaporation duct height.

\begin{tabular}{lcccccccccccccccc}
\hline Link & \multicolumn{4}{c}{$M$ profile 1 } & \multicolumn{4}{c}{$M$ profile 2 } & \multicolumn{4}{c}{$M$ profile 3 } & \multicolumn{4}{c}{$M$ profile 4 } \\
EDH $(\mathrm{m})$ & $0 \mathrm{~m}$ & $10 \mathrm{~m}$ & $20 \mathrm{~m}$ & $30 \mathrm{~m}$ & $0 \mathrm{~m}$ & $10 \mathrm{~m}$ & $20 \mathrm{~m}$ & $30 \mathrm{~m}$ & $0 \mathrm{~m}$ & $10 \mathrm{~m}$ & $20 \mathrm{~m}$ & $30 \mathrm{~m}$ & $0 \mathrm{~m}$ & $10 \mathrm{~m}$ & $20 \mathrm{~m}$ & $30 \mathrm{~m}$ \\
\hline Link 1 & 0.20 & -0.09 & 0.13 & -0.15 & 0.17 & 0.17 & 0.18 & 0.02 & 0.17 & 0 & 0.02 & 0 & 0.05 & -0.01 & -0.02 & 0.01 \\
Link 2 & 0.29 & 0.31 & 0.01 & -0.11 & 0.24 & 0.07 & 0.11 & -0.02 & 0.32 & 0.34 & 0.11 & 0.06 & 0.25 & 0.12 & 0.17 & 0.06 \\
\hline
\end{tabular}

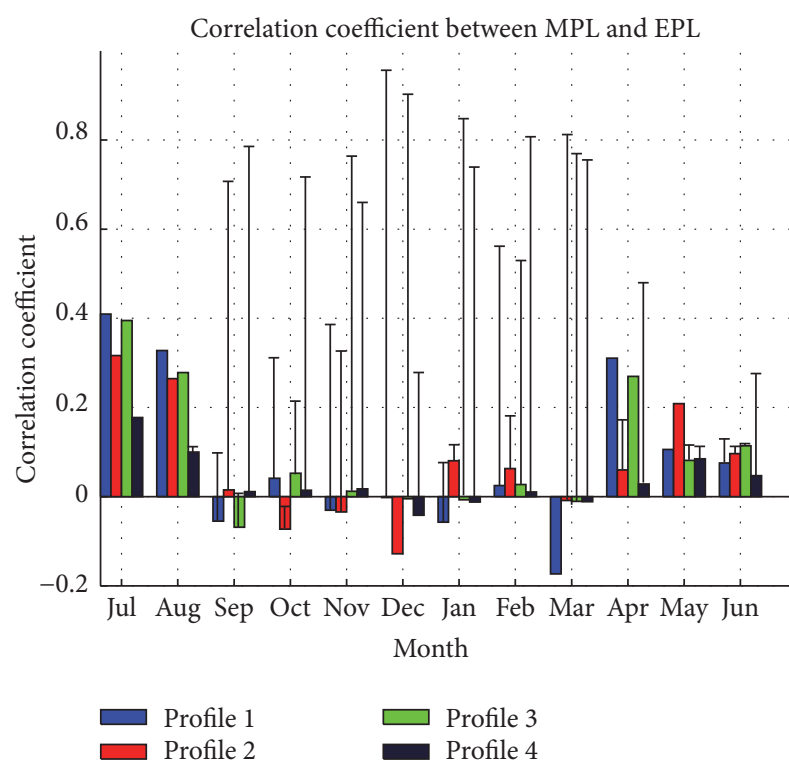

(a)

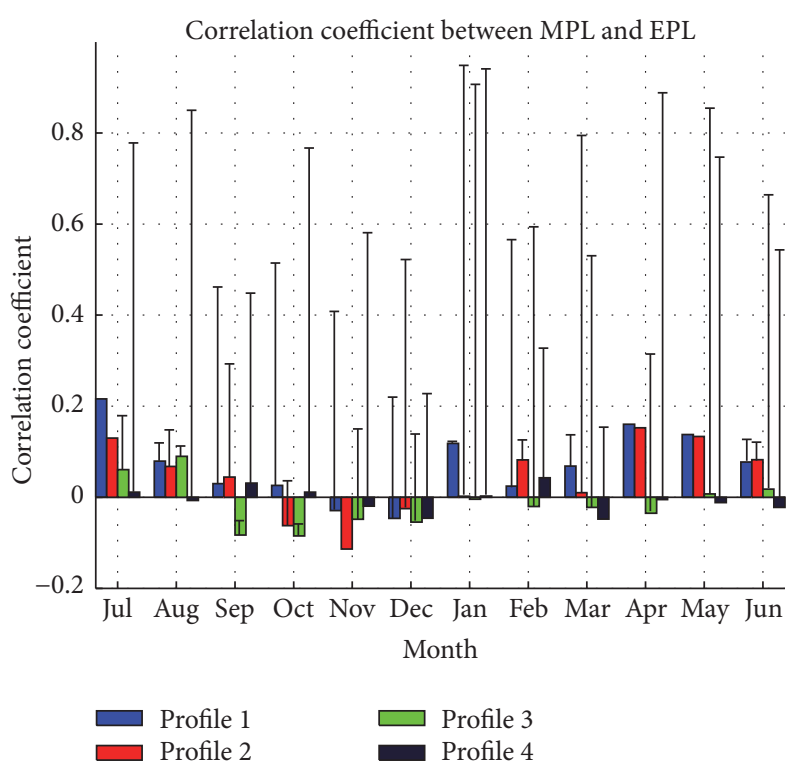

(c)

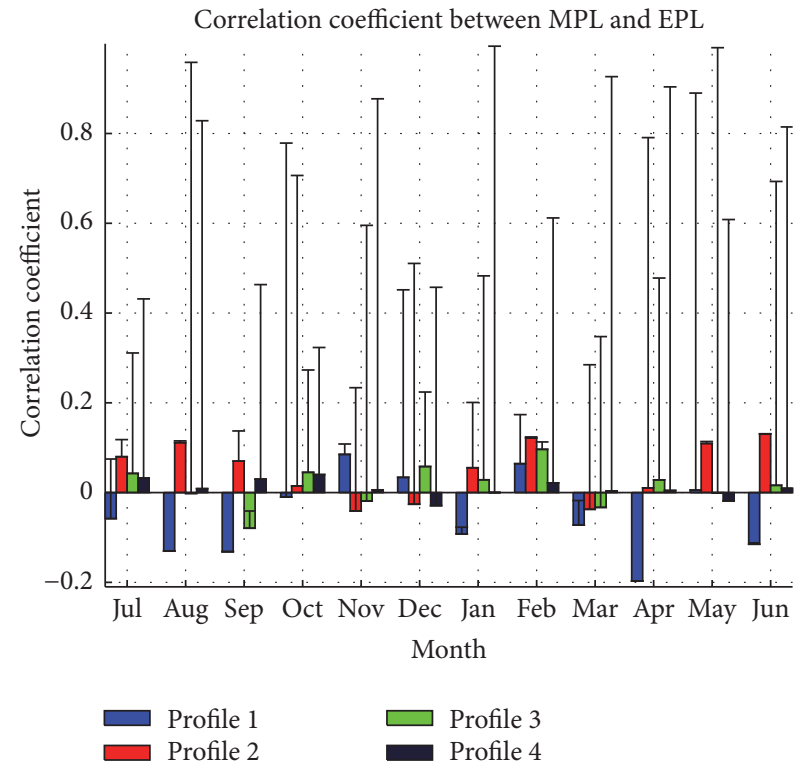

(b)

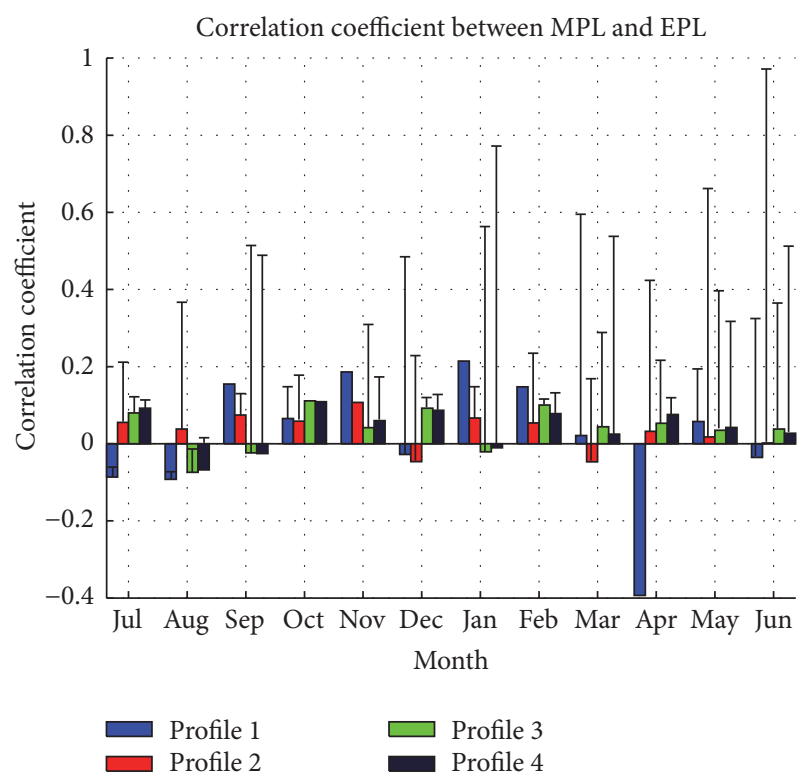

(d)

Figure 1: Monthly correlation coefficients for different $M$ profiles for "Link 1" in case of (a) $0 \mathrm{~m} \mathrm{EDH,} \mathrm{(b)} 10 \mathrm{~m} \mathrm{EDH,} \mathrm{(c)} 20 \mathrm{~m}$ EDH, and (d) $30 \mathrm{~m} \mathrm{EDH}$. The bar and line represent the correlation coefficient and $p$ value, respectively. MPL and EPL are the modelled path loss and experimental path loss, respectively. 


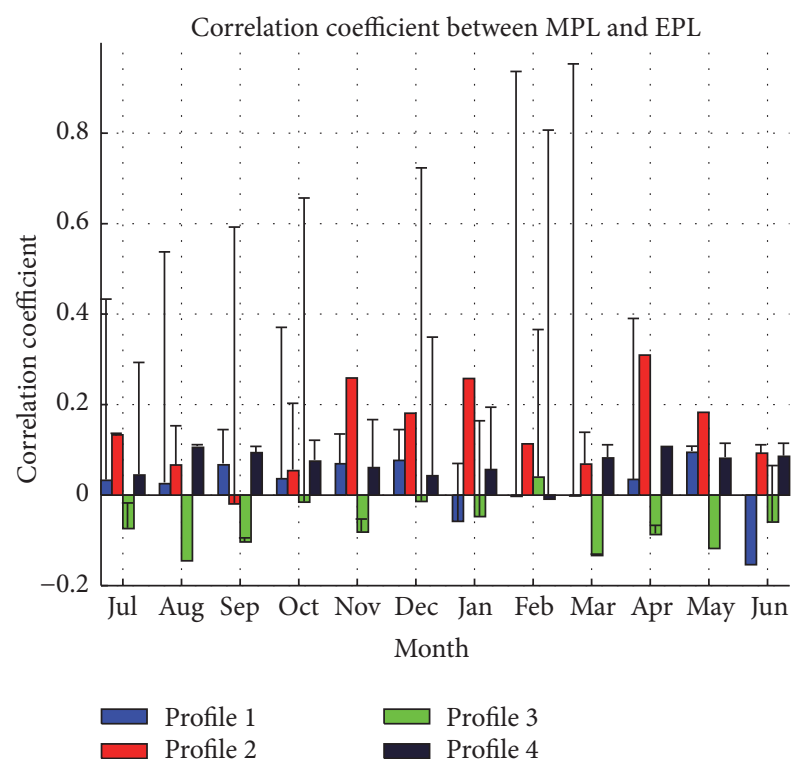

(a)

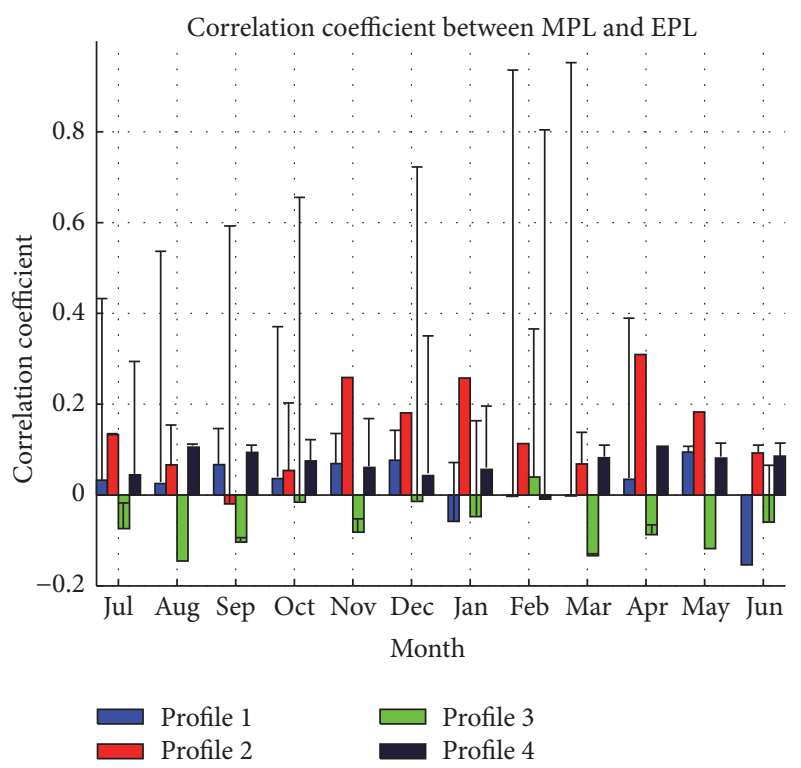

(c)

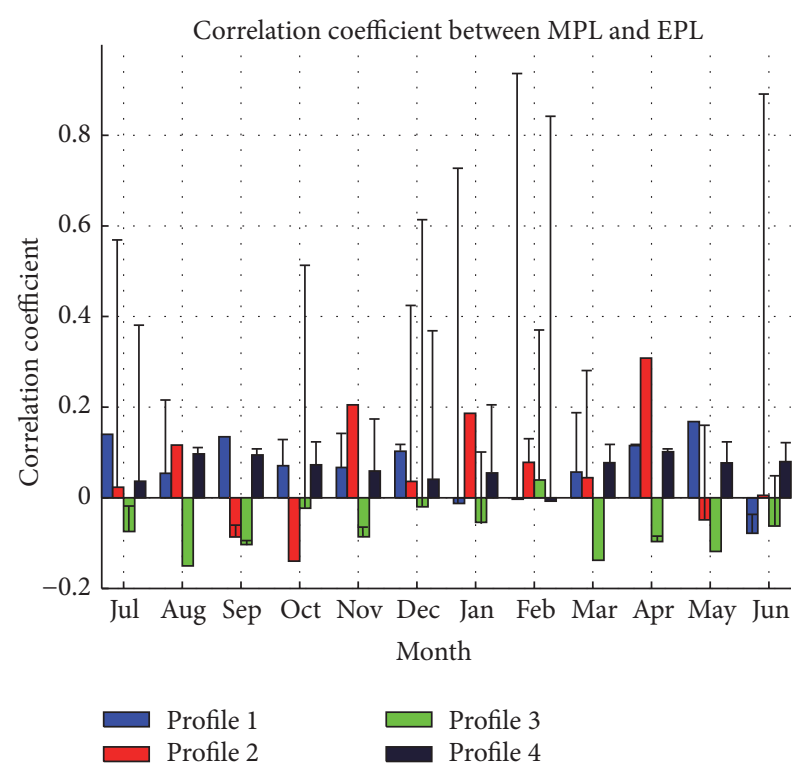

(b)

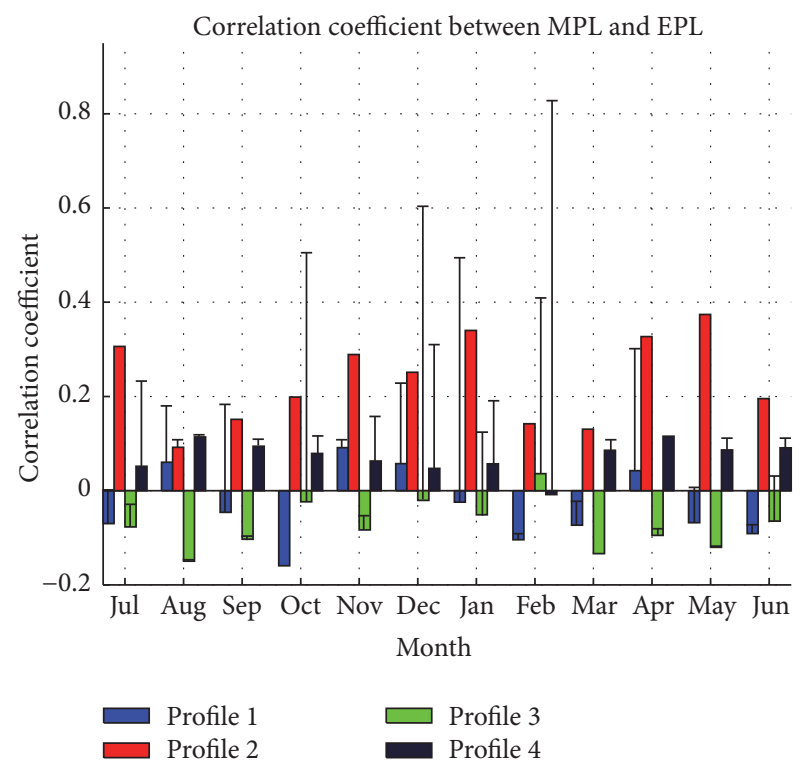

(d)

Figure 2: Monthly correlation coefficients for different $M$ profiles for "Link 2" in case of (a) $0 \mathrm{~m} \mathrm{EDH,} \mathrm{(b)} 10 \mathrm{~m} \mathrm{EDH,} \mathrm{(c)} 20 \mathrm{~m}$ EDH, and (d) $30 \mathrm{~m} \mathrm{EDH}$. The bar and line represent the correlation coefficient and $p$ value, respectively. MPL and EPL are the modelled path loss and experimental path loss, respectively.

May. Although there are some changes in the EPL, there are very little or rather no changes in the corresponding value of MPL throughout the month of May.

The behaviour of smooth MPL is analyzed for the whole year (results not shown here), and it is found to be the same throughout the year. Therefore, it is concluded that the effect of variations in refractivity is not severe for the long path at VHF. In order to validate this result, some more results (Not shown here) are analyzed for the same period with " $M$ profile 4," where it can be seen that the tidal patterns are changing the MPL alone when compared to the results and therefore refractivity variations are not affecting the signal at VHF frequency over the sea.

\section{Conclusion}

The objective of this research was to investigate the effect of variations in refractivity for oversea UHF $(2015 \mathrm{MHz})$ and VHF $(240 \mathrm{MHz})$ propagation at different heights and time. A communication network was set up over the English Channel for two communication links where a high resolution data of 6000 values of signal strength per hour was recorded for a period of a year for each communication link. Since the research is about oversea paths only, so a limited height over the sea was considered as a region of interest where the influence of evaporation duct upon path loss is more dominant. In this region the ducting of the signal due to the 
local meteorological variables may result in a considerable reduction in path loss of each communication link. However, it is a very difficult phenomenon as the trapping of a signal in a duct depends not only on the frequency of the propagating wave but also on the incidence angle. The effect of changing the evaporation duct height on propagation was investigated.

Based on the combined monthly and annual analysis presented in this research for the modelled and experimental observations over the sea, it is concluded that for UHF waves propagating on a long path of $140 \mathrm{~km}$, the strongest correlation between experimental and modelled path losses occurs when the evaporation duct is absent from the model. It means that the propagating signal is mostly affected by the evaporation duct in case of "Link 2" while there is no effect of evaporation duct on propagation in case of "Link 1." It is also concluded that there is, comparatively, less effect of evaporation duct on propagation in case of UHF. The standard refractivity profile is found to be the best for the UHF frequency while the ITU recommended refractivity profile work better than the standard profile for the VHF frequency.

\section{Competing Interests}

The authors declare that they have no competing interests.

\section{Acknowledgments}

The authors gratefully acknowledge the British Atmospheric Data Centre (BADC) and the UK Meteorological Office for providing access to meteorological data. Part of this work is performed while staying at the University of Leicester, UK, for which the authors gratefully acknowledge University of Leicester.

\section{References}

[1] A. Karimian, C. Yardim, P. Gerstoft, W. S. Hodgkiss, and A. E. Barrios, "Refractivity estimation from sea clutter: an invited review," Radio Science, vol. 46, no. 6, 2011.

[2] M. A. Leontovich, "A new method to solve problems of EM wave propagation over the earth surface," Bulletin of the USSR Academy of Sciences, Physics Series, vol. 8, no. 1, pp. 16-22, 1944.

[3] M. A. Leontovich and V. A. Fock, "Solution of the problem of propagation of electromagnetic waves along the earth's surface by the method of parabolic equation," Journal of Physics of the USSR, vol. 10, no. 1, pp. 13-24, 1946.

[4] F. D. Tappert, “The parabolic approximation method," in Wave Propagation and Underwater Acoustics, vol. 70 of Lecture Notes in Physics, chapter 5, pp. 224-287, Springer, Berlin, Germany, 1977.

[5] D. Lee and A. D. Pierce, "Parabolic equation development in recent decade," Journal of Computational Acoustics, vol. 3, no. 2, pp. 95-173, 1995.

[6] K. H. Craig, "Propagation modelling in the troposphere: parabolic equation method," Electronics Letters, vol. 24, no. 18, pp. 1136-1139, 1988.

[7] J. R. Kuttler and G. D. Dockery, "Theoretical description of the parabolic approximation/Fourier split-step method of representing electromagnetic propagation in the troposphere," Radio Science, vol. 26, no. 2, pp. 381-393, 1991.

[8] K. H. Craig and M. F. Levy, "Parabolic equation modelling of the effects of multipath and ducting on radar systems," IEE Proceedings, Part F: Radar and Signal Processing, vol. 138, no. 2, pp. 153-162, 1991.

[9] F. J. Ryan, "Analysis of electromagnetic propagation over variable terrain using the parabolic wave equation," Tech. Rep. 1453, AD-A 248 061, NOSC (Naval Ocean System Centre), San Diego, Calif, USA, 1991.

[10] A. E. Barrios, "A terrain parabolic equation model for propagation in the troposphere," IEEE Transactions on Antennas and Propagation, vol. 42, no. 1, pp. 90-98, 1994.

[11] G. D. Dockery and J. R. Kuttler, "An improved impedanceboundary algorithm for Fourier split-step solutions of the parabolic wave equation," IEEE Transactions on Antennas and Propagation, vol. 44, no. 12, pp. 1592-1599, 1996.

[12] M. Born and E. Wolf, Principles of Optics: Electromagnetic Theory of Propagation, Interference and Diffraction of Light, chapter 1, 3, 8, Cambridge University Press, New York, NY, USA, 7 th edition, 1999.

[13] E. Mach, The Principles of Physical Optics-An Historical and Philosophical Treatment, Dover, New York, NY, USA, 1953.

[14] J. R. Wait, "Coupled mode analysis for a nonuniform tropospheric wave guide," Radio Science, vol. 15, no. 3, pp. 667-673, 1980.

[15] L. B. Felsen and T. Ishihara, "Hybrid ray-mode formulation of ducted propagation," The Journal of the Acoustical Society of America, vol. 65, no. 3, pp. 595-607, 1979.

[16] G. D. Dockery, "Modeling electromagnetic wave propagation in the troposphere using the parabolic equation," IEEE Transactions on Antennas and Propagation, vol. 36, no. 10, pp. 14641470, 1988.

[17] M. F. Levy, Parabolic Equation Methods for Electromagnetic Wave Propagation, vol. 45, The Institution of Electrical Engineers, London, UK, 1st edition, 2000.

[18] O. Ozgun, G. Apaydin, M. Kuzuoglu, and L. Sevgi, "PETOOL: MATLAB-based one-way and two-way split-step parabolic equation tool for radiowave propagation over variable terrain," Computer Physics Communications, vol. 182, no. 12, pp. 26382654, 2011.

[19] G. Apaydin and L. Sevgi, "MatLab-based FEM-Parabolicequation tool for path-loss calculations along multi-mixedterrain paths," IEEE Antennas and Propagation Magazine, vol. 56, no. 3, pp. 221-236, 2014.

[20] G. Apaydin and L. Sevgi, "A novel split-step parabolic-equation package for surface-wave propagation prediction along multiple mixed irregular-terrain paths," IEEE Antennas and Propagation Magazine, vol. 52, no. 4, pp. 90-97, 2010.

[21] L. Sevgi, Ç. Uluışık, and F. Akleman, "A MATLAB-based two-dimensional parabolic equation radiowave propagation package," IEEE Antennas and Propagation Magazine, vol. 47, no. 4, pp. 164-175, 2005.

[22] G. D. Smith, Numerical Solution of Partial Differential Equation: Finite Difference Methods, The Clarendon Press, Oxford, UK, 2nd edition, 1978.

[23] N. Mufti, Investigation into the effect of the troposphere on $V H F$ and UHF radio propagation and interference between cofrequency fixed links [Ph.D. thesis], Department of Engineering, University of Leicester, Leicester, UK, 2011. 
[24] R. H. Hardin and F. D. Tappert, "Application of the split-step Fourier method to the numerical solution of nonlinear and variable coefficient wave equations," SIAM Review, vol. 15, p. 423, 1973.

[25] M. Grabner and V. Kvicera, Atmospheric Refraction and Propagation in Lower Troposphere, chapter 7, InTech, 2011.

[26] L. Barclay, Propagation of Radiowaves, The Institution of Electrical Engineers, London, UK, 2nd edition, 2003.

[27] International Telecommunication Union, "The radio refractive index: its formula and refractivity data," Tech. Rep. ITU-R P.45310, The Recommendation of International Telecommunication Union, P Series, Radiowave Propagation, 2012.

[28] A. Villarreal and J. A. Scales, "Distributed three-dimensional finite-difference modeling of wave propagation in acoustic media," Computers in physics, vol. 11, no. 4, pp. 388-399, 1997. 


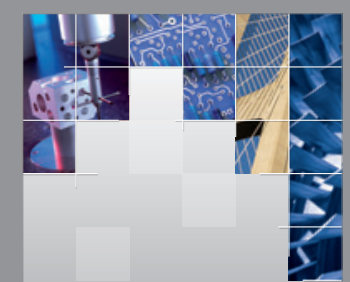

\section{Enfincering}
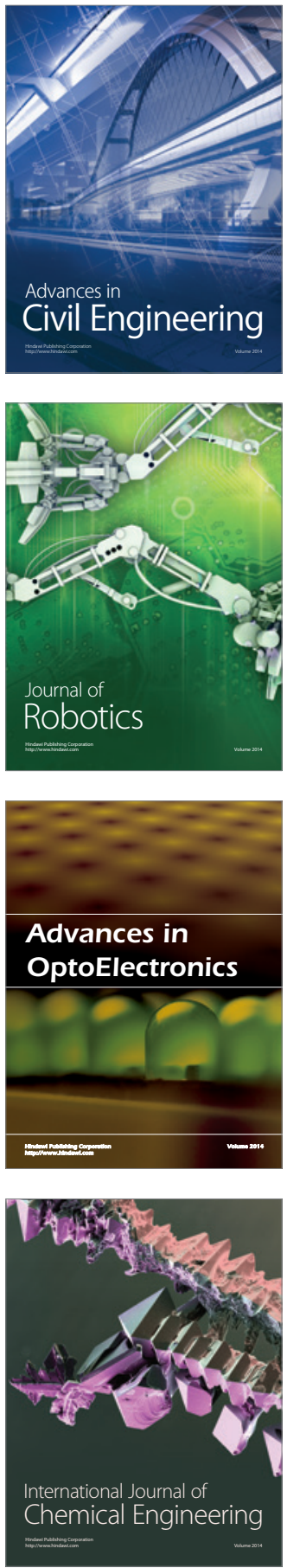

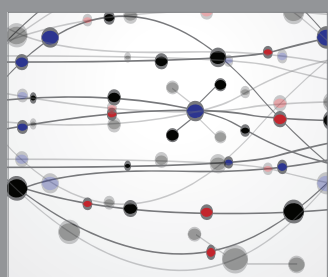

The Scientific World Journal

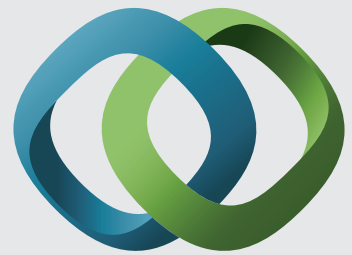

\section{Hindawi}

Submit your manuscripts at

http://www.hindawi.com
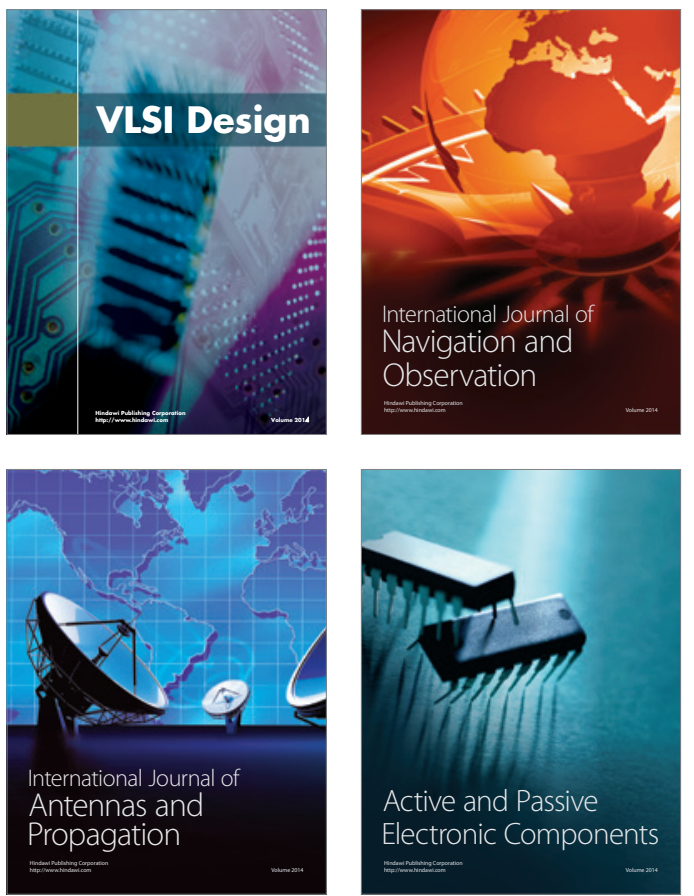
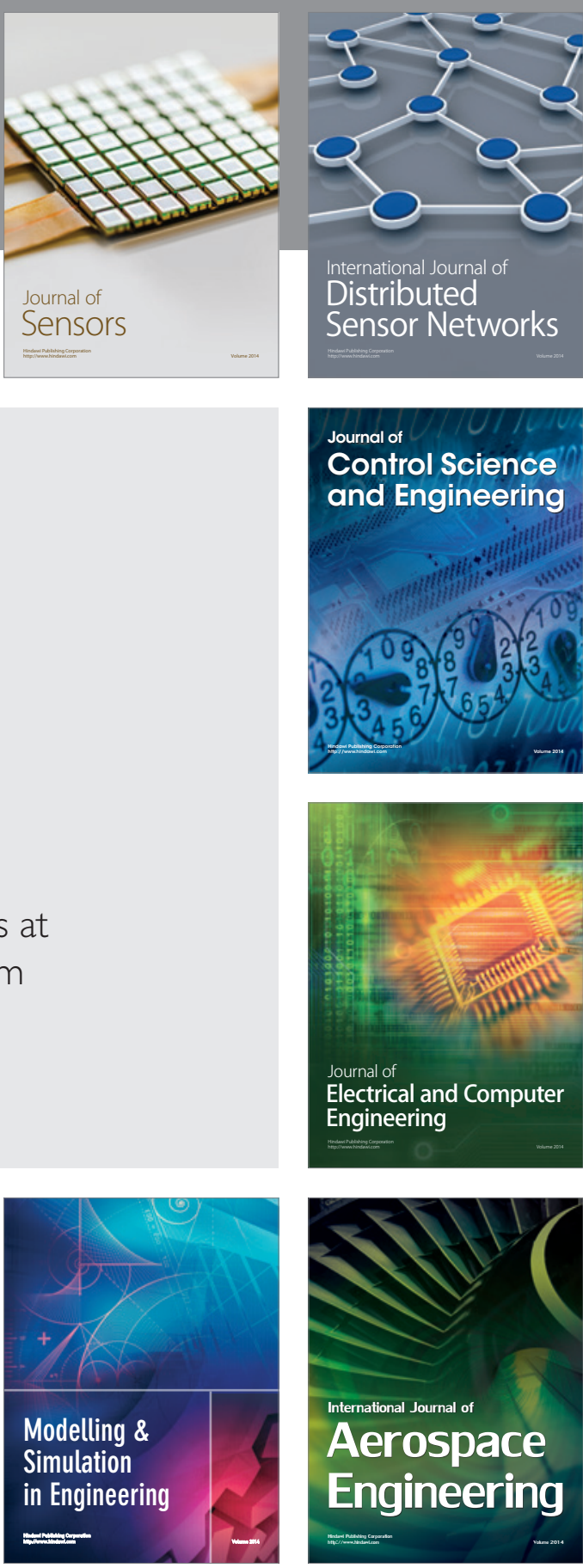

International Journal of

Distributed

Sensor Networks

Journal of

Control Science

and Engineering
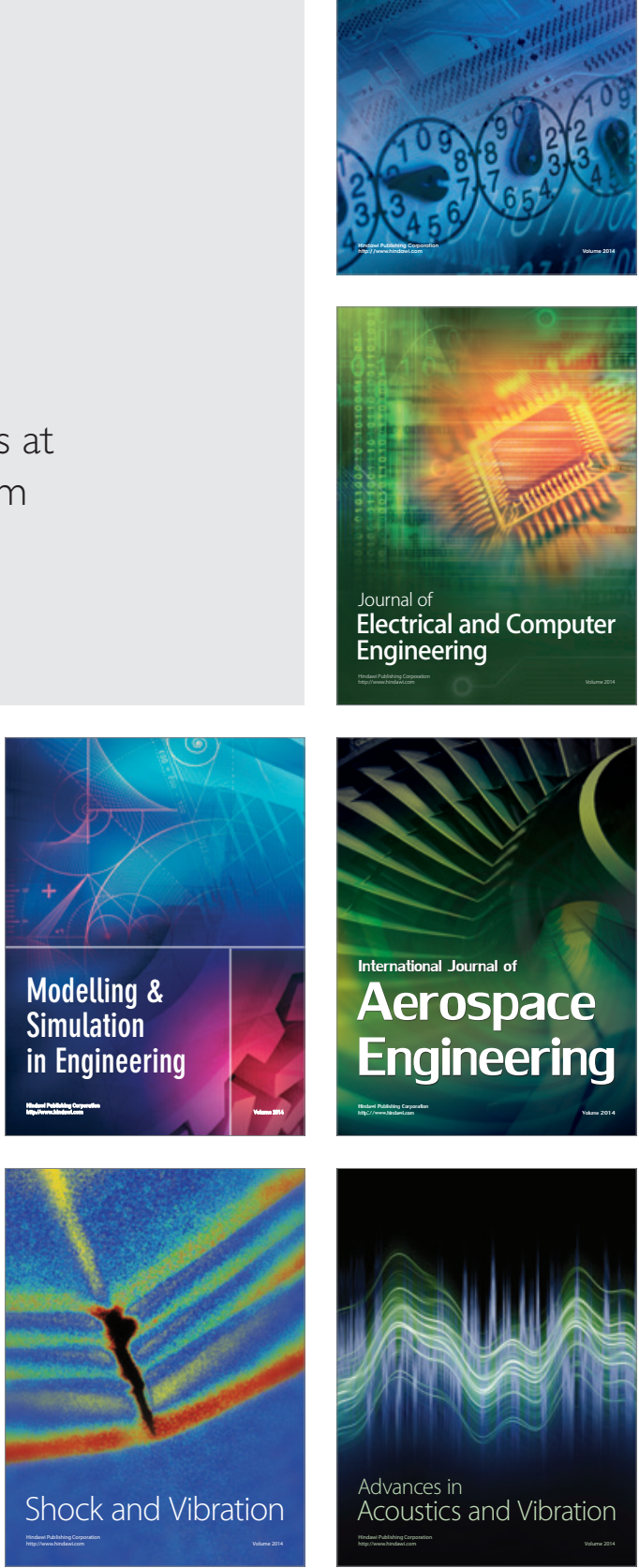